\title{
Determination of the Molecular Weight OF THE iNitrocellulose Binder
}

IN PBX 9404

R. A. Blythe

QUALITY DIVISION

JANUARY - MARCH 1976

Normal Process Development

Endeavor No. 223

\section{年}

? 


\section{DISCLAIMER}

This report was prepared as an account of work sponsored by an agency of the United States Government. Neither the United States Government nor any agency Thereof, nor any of their employees, makes any warranty, express or implied, or assumes any legal liability or responsibility for the accuracy, completeness, or usefulness of any information, apparatus, product, or process disclosed, or represents that its use would not infringe privately owned rights. Reference herein to any specific commercial product, process, or service by trade name, trademark, manufacturer, or otherwise does not necessarily constitute or imply its endorsement, recommendation, or favoring by the United States Government or any agency thereof. The views and opinions of authors expressed herein do not necessarily state or reflect those of the United States Government or any agency thereof. 


\section{DISCLAIMER}

Portions of this document may be illegible in electronic image products. Images are produced from the best available original document. 


\section{NOTICE}

This report was prepared as an account of work sponsored by the United States Government. Neither the United States nor the United States Energy Research and Development Administration, nor their employees, nor any of their contractors, subcontractors, or their employees, makes any warranty, express or implied, or assumes any legal liability or responsibility for the accuracy, completeness or usefulness of any information, apparatus, product or proness diselnserl, or represents that its use wnuld not infringe privately-owned rights. 


\title{
Determination of the Molecular Weight of the Nitrocellulose Binder in PBX 9404
}

\author{
R. A. Blythe
}

QUALITY DIVISION:

\author{
January - March 1976 \\ Crideavorn Nu. 223
}

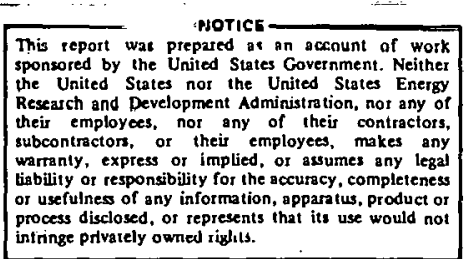

process disclosed, or represents
intringe privately owned rights.

V-1

DISTRIBUTION OF THIS DOCUMENT IS UNLIMITED

DISTRIBUTION OF THIS DOCUMENT IS UNLIMITED 


\section{ABSTRACT}

A method has been developed for making molecular weight determinations of the nitrocellulose binder in PBX 9404. A 3\% sample of PBX 9404 in tetrahydrofuran (THF) is ana ly.zed by Gel Permeation Chromatography (GPC). Molecular weights are calculated in the classical manner.

\section{INTRODUCTION}

The nitrocellulose (NC) binder in PBX 9404 is the most labile component and the useful life of the explosive depends upon the NC binder retaining its mechanical integrity. Little information about the molecular weight of NC was available from literature so an intensive characterization study was undertaken.

The number average molecular weight $(\bar{M} n)$ and the weight average molecular weight $(\bar{M} w)$ are of primary concern. A decrease in the molecular weights and an accompanying increase in the polydispersity (molecular weight distribution) would indicate a degradation of the binder caused by chain cleavage. Such a degradation of the binder would eventually lead to mechanical failure of the explosive.

GPC provides a relatively rapid method for determining molecular weights and molecular weight distributions of most polymeric substances(1). After some experimentation, it was determined that good separations of PBX 9404 components could be obtained by GPC analysis (see Fig. 1).

\section{EXPERIMENTAL}

\section{APPARATUS}

Gel Permeation Chromatograph: Waters Model 200 with R1 detector. Solvent: Tetrahydrofuran

Columns: Two each $10^{6}$ and two each $10^{4}$ Angstrom Styragel

Flow: $1 \mathrm{me} / \mathrm{min}$

Oven Temperature: $30 \mathrm{C}$

\section{SAMPLE PREPARATION}

Samples (0.6 gram) of PBX 9404 were dissolved in $20 \mathrm{me}$ of THF to give a nitrocellulose concentration of approximately $0.09 \%$. Samples were manually shaken to prevent degradation of the polymer that might be caused by ultrasonic or mechanical agitation. The sample was introduced via a sampling valve fitted with a $2.0 \mathrm{me}$ loop without further dilution.

\footnotetext{
(1) K. H. Altgelt and Leon Segal, Gel Permeation Chromatography, Marcel Dekker, Inc., New York (1971).
} 


\section{DISCUSSION}

The first goal of the characterization study was to determine whether NC was soluble in any of the common GPC solvents and if so, what concentration would be required for analysis. NC was found to be soluble in tetrahydrofuran up to $4 \%$ by weight. HMX is soluble only to about $0.75 \%$ by weight. Initially, $1 \%$ samples of PBX 9404 (approximately $0.03 \%$ NC) were run and good separations obtained. However, peak heights were not sufficiently. large for accurate measurement.

A series of PBX 9404 samples from $1 \%$ to $5 \%$ in $1 \%$ increments was analyzed by GPC and the $3 \%$ mixture was selected as giving the best peak height. with a 3\% PBX 9404 solution, the NC concentration is only a nominal $0.09 \%$, requiring that the RI detector be operated at $16 \mathrm{X}$, the maximum sensitivity. At this concentration, the solution is saturated with HMX and approximately 0.2 gram of HMX does not dissolve. All of the NC dissolves, however. At concentrations up to $12 \%$ PBX $9404(0.36 \% \mathrm{NC})$, all the NC appears to go into solution, evidenced by successive chromatograms at different concentrations. Molecular weights are obtained by comparison against a polystyrene standard calibration curve. Narrow distribution polystyrene standards of known molecular size are analyzed by GPC and the retention volume ( $1 \mathrm{RV}=5 \mathrm{~m}$ ) plotted against the $\log$ of the angstrom size of the standard. The angstrom size of unknown samples can then be determined by comparing the retention volume of the unknowns against the calibration curve. The angstrom size of a polymer depends upon the volume occupied by the molecule which is in turn dependent. upon the extended chain length, the fixed end to end distance, and the random coiling effects of the molecule. Thus, the angstrom size of two polymers of identical molecular weight will probably not be identical.

Molecular size is converted to molecular weight by the use of a $Q$ factor, i.e., the number of molecular weight units per angstrom of molecular size. The $Q$ factor is different for different polymers. For polystyrene, the $Q$ factor is 41.4 and in much GPC work, the polystyrene $Q$ factor is used for other polymers whose $Q$ factor is unknown in order to provide a common reference. Until recently, all molecular weight determinations in this laboratory were expressed relative to polystyrene. In an effort to determine absolute molecular weights, a new Q factor of 14.5 was determined for nitrocellulose by vapor pressure osmometry(2).

Approximately one hundred samples of PBX 9404 have been analyzed in at least duplicate on the GPC. All available library samples have been run as controls. A preliminary analys is of the results indicates that results are reproducible to within $\pm 7 \%$. Two samples which had been run in quadruplicate were further analyzed statistically. For both samples the $95 \%$ confidence levels fall within $\pm 7 \%$ of the mean molecular weights. (See Table I for complete data.) It should be noted that all raw data have been rounded to three significant digits, and that all molecular weights were calculated using the recently determined $Q$ factor of 14.5.

(2) C. S. MacDougall, "Determination of Absolute Molecular Weights of Nitrocollulose by Gal Pormoation Chromatography;" MHSMP.75-10P, (July-September 1975). 


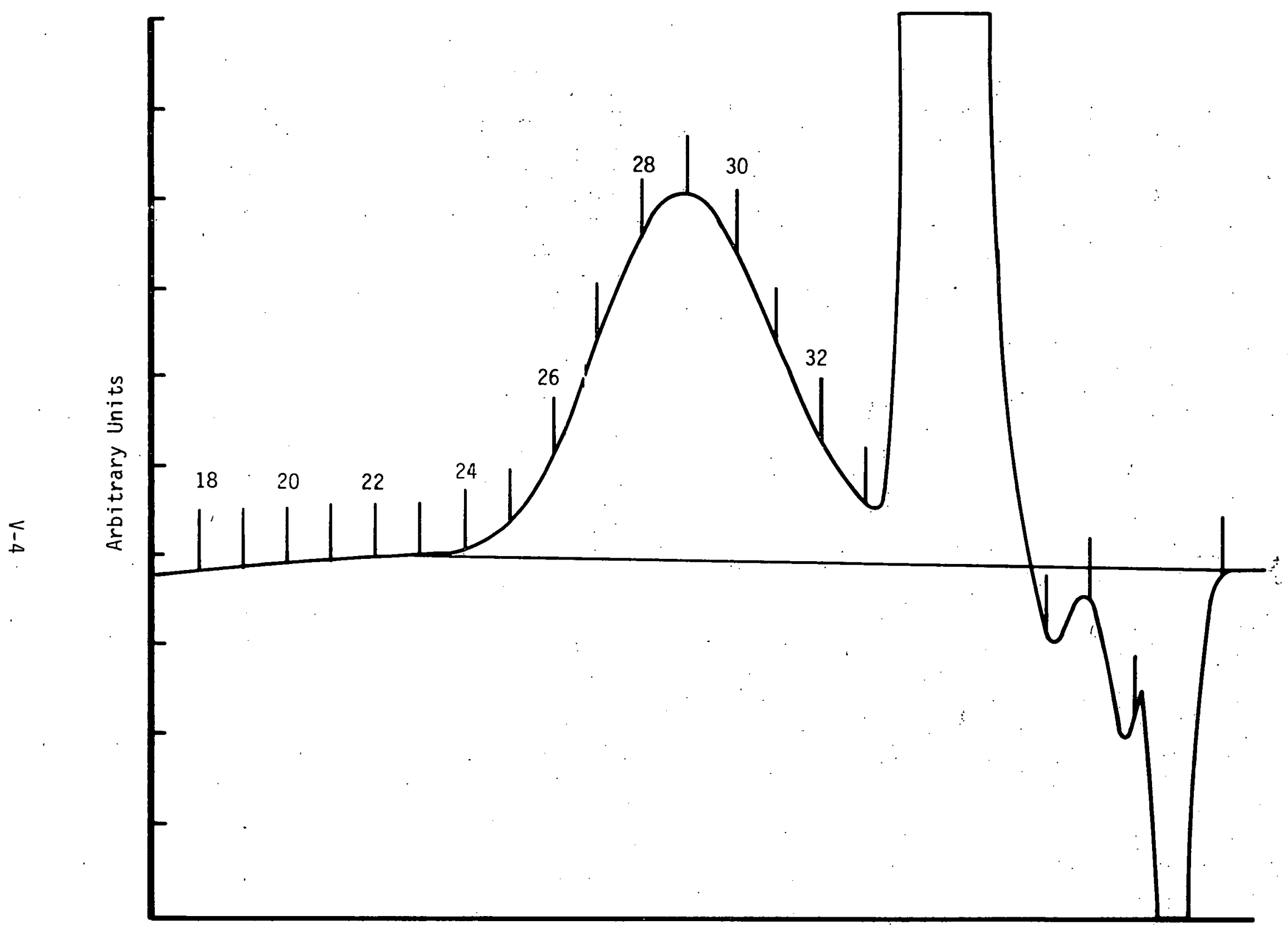

Elution Volume (1 Plark $=5 \mathrm{ml}$ )

Fig. 1. GPC Scan for PBX 9404 
Table I. Standard Deviations for Molecular Weights

of Nitrocellulose in Two Samples of PBX 9404

$$
\begin{aligned}
& \begin{array}{l}
\text { Run } \\
\text { No }
\end{array} \\
& 1 \\
& 2 \\
& 3 \\
& 4
\end{aligned}
$$

Run

No.

1
2
3
4

Average

4273

10,575

2.47

Std. Dev.

137.20

287.23

95\%.Conficence Level: : $\bar{M} n 3999$ to 4547

$\bar{M}_{W} \quad 10,001$ to 11,149

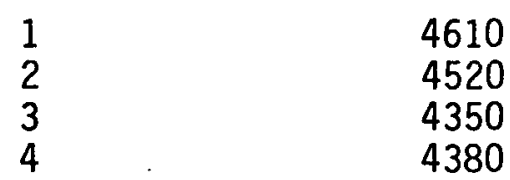

11,700

2.53

11,700

2.59

11,400

2.63

11,400

2.59

Average

4465

11,550

2. 58

Std. Dev.

121.79

173.21

95\% Confidence Level: $\bar{M}$ n 4221 to 4709

$\overline{M w} 11,204$ to 11,896

${ }^{*} Q=14.5$ 


\section{CONCLUSIONS}

A satisfactory method has been developed for determining the molecular weights and the molecular weight distributions of the nitrocellulose binder in PBX 9404. Three percent samples of the explosive in THF were analyzed by GPC. All available library samples of the explosive have been analyzed as have various samples subjected to field storage and artificial aging. To date, no significant deterioration has been discovered. This method will reveal any significant shifts in molecular weight caused by chain cleavage in the binder and should provide warning of possible mechanical failure of the explosive.

\section{ACKNOWLEDGEMENT}

The author is indebted to F. L. Hamilton and R. G. Watson for their assistance in the daily operation of the gel permeation chromatograph, and for the many changes made to the instrument in developing and improving the technique. 